\title{
FRENCH TERMINOLOGY OF SPELEOLOGICAL FORMS
}

\section{FRANCOSKA TERMINOLOGIJA SPELEOLOŠKIH OBLIK}

\author{
JACQUES CHOPPY \\ 182, rue de Vaugirard, 75015 PARIS, FRANCE
}

COBISS: 1.21

\section{THE DESCRIPTION OF FORMS AND CAVES}

The aim of terminology of speleological forms is to describe these forms, and a cave is an assembly of forms.

In France, terms of common language were first used, such as entrée ( entrance »), draperie (« drapery », « curtain »), etc. and a few terms of scientific origin such as stalagmite.

Then speleologists realized that it was possible to describe forms by their geometry. Thus such terms as cône d'éboulis (« talus cone ») or " tube » were used. When the geometry is detailed, the description is more precise: the information is better when we know that there is a «ceiling channel» above the tube or that a stalagmite is presented as a « hollow stalagmite ».

Often a « group » of identical forms can be identified in a limited zone, whereas there are no such forms in other parts of the cave. This is often the case with potholes or soda straws for instance. This type of observation improves the quality of description.

There is also what can be presented as « associated forms »:

Certain speleological forms are associated with one another: a sinkhole corresponds to a resurgence; a stalactite corresponds to a stalagmite. A group and the zone of the cave where it can be observed are also associated forms.

Other speleological forms are associated with a geological form: a contact sinkhole between two rocks of different solubility, dip tube, stalactites aligned along a crack.

Other forms are associated with a geographical form: a flowing cave opening at the level of a surface stream, deposit of rounded pebbles in a surface stream sinkhole.

There are also genetic terms; the most used being "phreatic» and "vadose ». These terms are useful for the interpretation of forms, but they are quite dangerous for the description of forms: if a passage is presented as «vadose », one does not know what are the forms justifying the word for the author. And if a tube is almost always presented as «phreatic », most of them have never been permanently filled with water, and some of them have never been filled with water. Genetic terms are deceptive. They must be avoided when forms are described.

\section{FROM DESCRIPTION TO INTERPRETATION}

A process is a chemical, physical or biological action governing the creation of speleological forms. Conversely certain forms can be considered as specific to one process. When the description is more detailed, the form is more likely to be considered as specific to one of the karst processes.

But for some forms, although they have a precise name, we have just seen that it would be 
unwise to consider them as specific. And if a group has necessarily a cause, associated forms may be fortuitous.

Nevertheless by observing specific forms, at least in one zone of the cave, one can discover phases of cave formation and/or sedimentation. Even in a rapid visit, as of a show cave, it is possible to detect a few of these stages. Sedimentological stratigraphy indicates the successive deposit phases. For the cave formation stages, only a few rare forms are specific to their succession.

Once it is admitted that the history of a cave is composed of a sequence of such phases, and then it is necessary to establish their chronology and to understand why they have followed one another. 